\title{
Testing of Google Earth Coordinates of Points in Baghdad City
}

\author{
Athraa Hashim Mohammed \\ Civil Engineering Department, Baghdad University, Baghdad, Iraq
}

\begin{abstract}
The popularity of Google earth all over the world is because of its providing a source of easy access and cost free image data for people who have interest in maps, as well as the increasing depending of explorers, navigators and other users on Google earth different facilities, but in spite of that this popularity is not an indication for its accuracy.This research is focusing on the accuracy of coordinates obtained from Google earth for a number of points in Baghdad city. This was done by comparing Google earth measured coordinates of points with Total station observed coordinates over sample of eleven check points in Baghdad university district in Baghdad city. Root mean square error (RMSE) was computed for coordinates and found to be $0.465 m$.
\end{abstract}

Keywords: Google Earth, Total Station, GCP, positional accuracy, GPS

\section{Introduction}

Google earth has become an infinite source of spatial data and information for private and public decision -support systems and many types and forms of social interactions. Individuals should concern the matter of data quality obtained from Google earth; however its inaccuracies are not expected to cause harm or damage in many cases. Google always aims to provide the users with more realistic view of the world.

There are other sources for spatial data, and positional measurements can be obtained using different methods like modern land survey methods, global positioning system (GPS), Total station, geographical information system technique and remote sensing satellite imagery. Each of those methods is of a known positional accuracy.

\section{Google Earth}

Google Earth is a geobrowser that accesses satellite and aerial imagery, ocean bathymetry, and other geographic data over the internet to represent the Earth as a threedimensional globe. Geobrowsers are alternatively known as virtual globes or Earth browsers. Google Earth maps the Earth by the superimposition of images obtained from satellite imagery, aerial photography and geographic information system (GIS) onto a 3D globe. It was originally available with three different licenses, but has since been reduced to just two: Google Earth (a free version with limited function) and Google Earth Pro, which is now free and is intended for commercial use. The third original option, Google Earth Plus, has been discontinued. The internal coordinate system of Google Earth is geographic coordinates (latitude/longitude) on the World Geodetic System of 1984 (WGS84) datum. Google Earth shows the earth as it looks from an elevated platform such as an airplane or orbiting satellite. The projection used to achieve this effect is called the General Perspective. This is similar to the Orthographic projection.

\section{Coordinate and Projection Systems}

There are three coordinate systems adopted in the different surveying operations, geographic coordinate system, geodetic coordinate system and projected coordinate system.

Geographic coordinate system is used to define the position of spatial features on the Earth's surface. The position of the spatial feature is referenced by its geographic longitude and latitude values. The earth ellipsoid only describes the size and shape of the earth. In order to accurately describe the specific position of features, we need to introduce the concept of geodetic coordinate system which determines the position of the earth ellipsoid compared to the earth core and provides a reference frame for the feature's measurement and positioning. The early measurement of the earth geodetic coordinate system is aimed to describe the surface situation of the measured region more comprehensively. In general, the ellipsoid in the geodetic coordinate system deviates from the real earth core. With the development of the earth measurement and space technique, people build global geodetic coordinate systems (such as WGS-66, WGS-72, WGS-84 and est.) by taking intercontinental and international measurement through geodesy measurement by satellite, and by integrating geographic, astronomic and earth gravity data. The most popularly applied geodetic coordinate system is WGS-84.

Map projection is the mathematical method for establishing the function relationship between the spot on the stereograph and the spot on the plane, the purpose of map projection is to turn the latitude net on the Earth into plane through special mathematical principles by which the position of a spot on the surface of the Earth is represented through geographic coordinates (latitude $\varphi$, longitude $\lambda$ ), while position of the spot on the plane is represented by Cartesian coordinates (ordinate $\mathrm{x}$, abscissa y) or polar coordinates ( polar radius $\delta$, polar angle $\rho$ ).

Based on the character of projection deformation, map projection is classified into three main types, conformal projection, equivalent projection and arbitrary projection. Based on the difference of projection surface, map projection is also divided into three types, conic projection, cylindrical projection and azimuthal projection. Based on the 


\section{International Journal of Science and Research (IJSR) \\ ISSN (Online): 2319-7064 \\ Index Copernicus Value (2013): 6.14 | Impact Factor (2014): 5.611}

position relation between projection surface and global spheroid, map projection is classified into three kinds, normal projection, transverse projection and oblique projection.

Pseudo projection is composed by pseudo-azimuthal projection, pseudo-conic projection and pseudo-cylindrical projection.

\section{Coordinates Measurements by Total Station}

The coordinates of an unknown point relative to a known coordinate can be determined using the total station as long as a direct line of sight can be established between the two points. Angles and distances are measured from the total station to points under survey, and the coordinates $(\mathrm{X}, \mathrm{Y}$, and $\mathrm{Z}$ or easting, northing and elevation) of surveyed points relative to the total station position are calculated using trigonometry and triangulation. To determine an absolute location a Total Station requires line of sight observations and must be set up over a known point or with line of sight to 2 or more points with known location.

For this reason, some total stations also have a Global Navigation Satellite System receiver and do not require a direct line of sight to determine coordinates.

\section{Field Measurements and Calculations}

To test the accuracy of points coordinates of Google earth a number of eleven points were selected in Baghdad city .These points were then observed using Nikon Total station, the base station was located in Baghdad university at fixed ground control points (GCP). Figure 1 shows a part of Google Earth image demonstrating the area of study and the ground control points in red color.

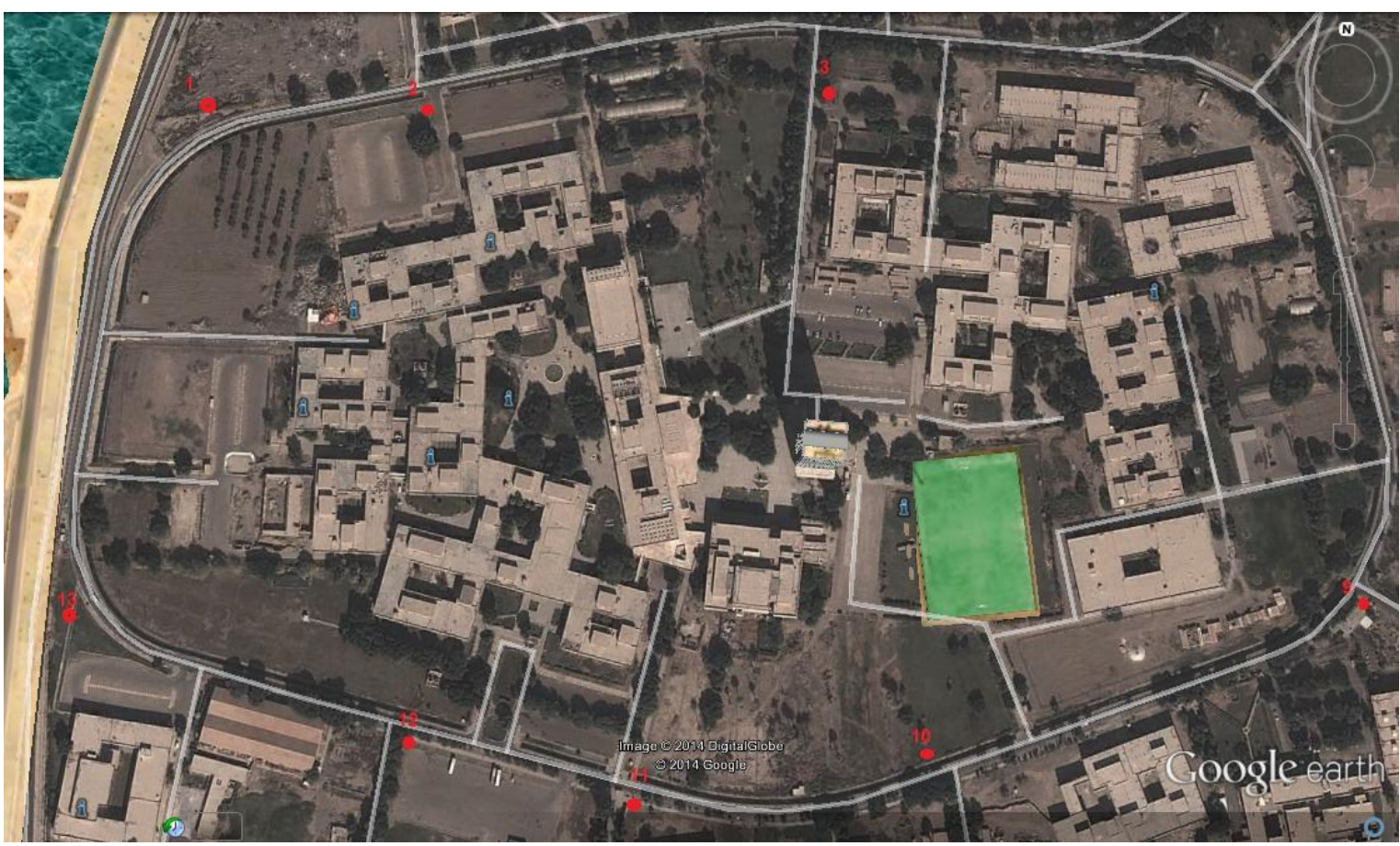

Figure 1: Study area and the ground control points 


\section{International Journal of Science and Research (IJSR) \\ ISSN (Online): 2319-7064}

Index Copernicus Value (2013): 6.14 | Impact Factor (2014): 5.611

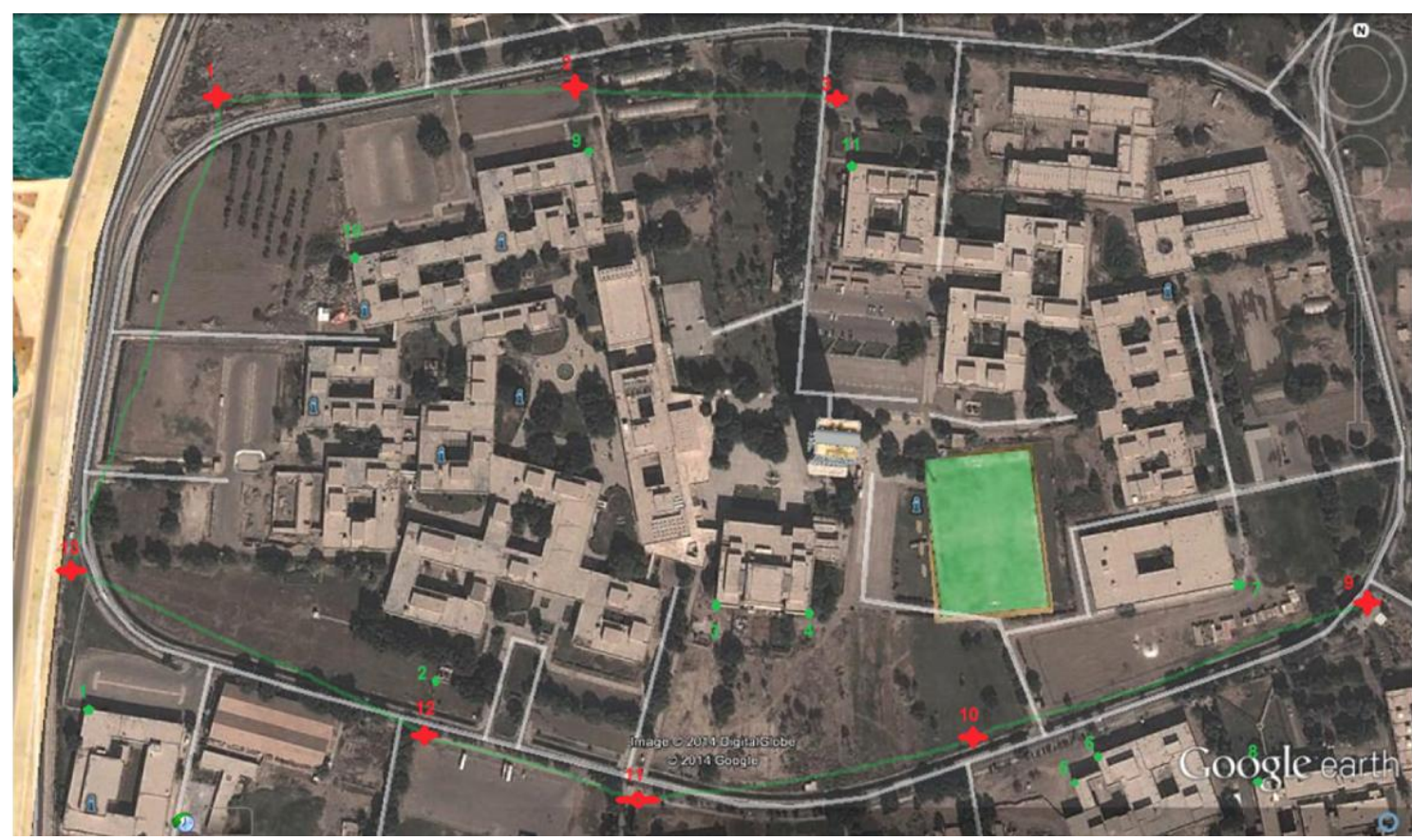

Figure 2: shows an enlarged image demonstrating the observed points in green color and the ground control points in red color

Results of Total station observations were tabulated in table 1

Table 1: Total station observed coordinates

\begin{tabular}{|c|c|c|}
\hline Point & \multicolumn{2}{|c|}{ Coordinates (Total Station) } \\
\hline 1 & $\mathrm{~N} 3681601.772$ & $\mathrm{E} 441525.041$ \\
\hline 2 & $\mathrm{~N} 3681633.614$ & $\mathrm{E} 441765.850$ \\
\hline 3 & $\mathrm{~N} 3681696.253$ & $\mathrm{E} 441956.141$ \\
\hline 4 & $\mathrm{~N} 3681692.840$ & $\mathrm{E} 442020.212$ \\
\hline 5 & $\mathrm{~N} 3681589.652$ & $\mathrm{E} 442205.133$ \\
\hline 6 & $\mathrm{~N} 3681607.522$ & $\mathrm{E} 442220.760$ \\
\hline 7 & $\mathrm{~N} 3681729.313$ & $\mathrm{E} 443217.573$ \\
\hline 8 & $\mathrm{~N} 3681594.830$ & $\mathrm{E} 442330.361$ \\
\hline 9 & $\mathrm{~N} 3682013.529$ & $\mathrm{E} 441846.137$ \\
\hline 10 & $\mathrm{~N} 3681926.800$ & $\mathrm{E} 441681.850$ \\
\hline 11 & $\mathrm{~N} 3682014.538$ & $\mathrm{E} 442036.012$ \\
\hline
\end{tabular}

Google Earth was used to measure the coordinates of eleven study points in 2015, table 2 shows the coordinates measured using Google Earth.

Table 2: Google Earth measured coordinates

\begin{tabular}{|c|c|c|}
\hline Point & Coordinates (Google Earth) \\
\hline 1 & N 3681601.51 & E 441525.40 \\
\hline 2 & N 3681633.87 & E 441765.70 \\
\hline 3 & N 3681696.68 & E 441955.76 \\
\hline 4 & N 3681693.62 & E 442020.16 \\
\hline 5 & N 3681590.20 & E 442205.21 \\
\hline 6 & N 3681607.86 & E 442220.55 \\
\hline 7 & N 3681729.47 & E 442317.96 \\
\hline 8 & N 3681595.30 & E 442330.16 \\
\hline 9 & N 3682013.61 & E 441846.37 \\
\hline 10 & N 3681926.65 & E 441682.07 \\
\hline 11 & N 3682014.88 & E 442036.04 \\
\hline
\end{tabular}

Differences between actual observed Total station coordinates of the points and the Google Earth measured coordinates were computed as listed below in table 3 .
Table 3: Differences between actual and Google Earth coordinates

\begin{tabular}{|c|c|c|}
\hline \multirow{2}{*}{ Points } & \multicolumn{2}{|c|}{ Deference in coordinates } \\
\cline { 2 - 3 } & $\Delta \mathrm{X}(\mathrm{m})$ & $\Delta \mathrm{Y}(\mathrm{m})$ \\
\hline 1 & 0.356 & -0.262 \\
\hline 2 & -0.15 & 0.256 \\
\hline 3 & -0.381 & 0.427 \\
\hline 4 & -0.052 & 0.78 \\
\hline 5 & 0.077 & 0.548 \\
\hline 6 & -0.21 & 0.338 \\
\hline 7 & 0.387 & 0.157 \\
\hline 8 & -0.201 & 0.47 \\
\hline 9 & 0.233 & 0.081 \\
\hline 10 & 0.22 & -0.15 \\
\hline 11 & 0.028 & 0.342 \\
\hline RMSE & 0.3967 & 0.2418 \\
\hline RMSE XY & \multicolumn{2}{|c}{0.465} \\
\hline
\end{tabular}

The root mean squared error (RMSE) was computed as accuracy indicator for coordinates $(\mathrm{X}, \mathrm{Y})$ and was found to be $0.465 \mathrm{~m}$

\section{Conclusion}

The using of Google Earth data by users in different disciplines make the specialists more rush to carry out researches for testing and evaluating the accuracy of Google Earth extracted data. From the measurements and results above, it can be concluded that:

1) There are differences between the actual and Google Earth coordinates of the chosen points, with $0.465 \mathrm{~m}$ RMSE as indicator for accuracy.

2) The difference in coordinates is not constant but it differs from point to another.

3) Even with the same point the difference is not the same in the $\mathrm{x}$ coordinate and the $\mathrm{y}$ coordinate.

4) The accuracy in Google earth data is improving with time. 


\section{International Journal of Science and Research (IJSR) \\ ISSN (Online): 2319-7064}

Index Copernicus Value (2013): 6.14 | Impact Factor (2014): 5.611

5) Google Earth data can be used in the projects that do not need a high accuracy like project studies, water surfaces studies, green and public spaces planning ....etc.

\section{References}

[1] Al-jawahry, Zuhair Abdulwahab, "Evaluation of Google EARTH coordinates accuracy", Karbalaa University, Engineering college, 2011.

[2] Becek, Ibrahim, "On the positional accuracy of Google Earth",

https://www.fig.net/resources/proceedings/fig_proceedi ngs/fig2011/papers/ts05i/ts05i_becek_ibrahim_4947.pdf

[3] projection.http://www.supermap.com/EN/online/Deskpr o\%206.0/SDTechTheme/html/Prj_Introduction.htm

[4] Stillman, Dm, "Plotting surveying data in Google Earth" https:/google-earthplotter.googlecode.com/files/Journal\%20Paper.pdf

[5] Surveying Instrument Measurements and Errors, http://www.mdt.mt.gov/other/photosurv/external/survey /manual_guides_forms/survey_manual/sm_chapter03.p df

[6] Total Station, http://cipa.icomos.org/fileadmin/template/doc/TURIN/1 13.pdf 